\title{
ANALISIS PERSEDIAAN BAHAN BAKU KEDELAI MENGGUNAKAN EOQ, ROP DAN SAFETY STOCK PRODUKSI TAHU BERDASARKAN METODE FORECASTING DI PT. LANGGENG
}

\author{
Rabiatus Sholehah ${ }^{1}$, Muhammad Marsudi ${ }^{1}$, Akhmad Ghiffary Budianto ${ }^{1}$ \\ ${ }^{1}$ Teknik Industri, Fakultas Teknik, Universitas Islam Kalimantan Muhammad Arsyad Al-Banjari \\ Jl. Adhyaksa, Jl. Kayu Tangi 1 Jalur 2 No.2, Sungai Miai, Kec. Banjarmasin Utara, Kota Banjarmasin, \\ Kalimantan Selatan 70123 \\ Email : rabiatus26@gmail.com
}

\begin{abstract}
Abstrak- Pengendalian persediaan merupakan aspek yang penting didalam dunia perindustrian, jika persediaan tidak diatur dengan baik maka akan berisiko terhadap keberlangsungan proses produksi. Dalam pengendalian persediaan terdapat beberapa metode yaitu EOQ, Safety Stock, dan juga ROP. Dalam memperhitungkan metode tersebut untuk kebetuhan mendatang selama 6 bulan diperlukan metode peramalan, metode Winter Multiplicative merupan metode peramalan terbaik dengan hasil nilai MAPE 6,5 untuk permintaan tahu putih dan 6,6 untuk permintaan tahu goreng, melalui data peramalan dapat diperhitungkan kebutuhan kedelai pada periode selanjutnya. Dalam perhitungan EOQ menggunakan data peramalan dihasilkan nilai sebesar 16.491 $\mathrm{kg}$ jumlah yang ekonomis untuk pemesanan dengan frekuensi pesan dari 24 kali menjadi 6 kali dalam periode waktu 6 bulan. Perhitungan biaya pesan yang lebih ekonomis sebesar Rp.708.959/bulan. Dalam perhitungan safety stock diperoleh hasil $862 \mathrm{~kg}$ untuk penyimpanan pengaman. Dan untuk hasil dari perhitungan ROP sebanyak $2.130 \mathrm{~kg}$ untuk batas minimum penyimpanan digudang untuk mempertimbangkan pembelian bahan baku kembali.
\end{abstract}

Kata Kunci : Metode Winter Multiplicative, EOQ, ROP, Safety Stock

\section{PENDAHULUAN}

$\mathrm{D}$ alam mencapai tujuan dari sebuah perusahaan dilakukan dengan cara memaksimalkan sumber daya pada setiap bagian yang dimiliki oleh perusahaan tersebut. Salah satu bagian penting dalam sebuah perusahaan industri adalah bagian proses produksi. Proses produksi akan mempengaruhi proses bisnis dalam perusahaan tersebut. Berlangsungnya proses produksi dipengaruhi oleh berbagai faktor salah satunya yaitu bahan baku. Sehingga setiap perusahaan dituntut untuk kerja lebih baik dalam men-set up struktur manajemen disetiap lini agar senantiasa sanggup menjawab tantangan demi tantangan yang akan terus ada. Ketika sebuah perusahaan berkembang, maka manajemen persediaannya semakin komplek. Disanalah manajemen persediaan menjadi objek penting karna bahan baku merupakan kompenen biaya produksi yang tinggi. Jika persediaan bahan baku tak dikelola dengan baik. Maka perusahaan tak akan mampu menaikan daya saing dan memiliki keunggulan kompetitif.

Kedelai merupakan bahan baku yang banyak dimanfaatkan dalam dunia perindustrian, Salah satunya pemanfaatan kacang kedelai sebagai bahan baku utama dari pembuatan tahu. Tahu meerupakan makanan khas Indonesia yang pembuatannya dengan menggunakan sari dari kedelai yang digumpalkan dan dicetak melalui beberapa proses seperti pengepresan agar kadar air yang ada ditahu berkurang. PT. Langgeng yang merupakan industri tahu yang memproduksi 2 jenis tahu, yaitu tahu putih dan tahu goreng. Dalam produksinya PT. Langgeng memelurkan bahan baku utama kedelai. PT. Langgeng mengalami peningkatan produksi yang signifikan antara bulan Maret 2021 hingga sekarang. Diperkirakan peningkatan produksi mencapai $66,6 \%$. Data yang di peroleh pada bulan Maret produksi perhari mencapai $300 \mathrm{~kg}$ dengan penggunaan minyak goreng 17 liter per hari sedangkan pada bulan April-sekarang produksi meningkat hingga mencapai $500 \mathrm{~kg}$ perhari dengan penggunaan minyak goreng mencapai 29 liter per hari.

Hal ini menjadi salah satu masalah yang sering muncul dalam persediaan bahan baku kedelai karna permintaan yang meningkat karena PT. Langgeng memproduksi tahu berdasarkan permintaan made by order dan juga pelanggang yang datang langsung ketempat produksi. PT. Langgeng pernah mengalami kerugian pada bulan April dikarenakan kehabisan stock bahan baku kedelai saat produksi akibat permintaan yang terus melonjak. Akibatnya PT. Langgeng tidak dapat memenuhi permintaan pada saat itu.

Pembengkakan biaya produksi terjadi saat bahan baku tidak cukup untuk memenuhi permintaan konsumen dikarenakan pihak dari PT. Langgeng harus menyiapkan biaya dadakan untuk pembelian kembali bahan baku kedelai. EOQ (Economic order quantity) merupakan metode manajemen persediaan yang digunakan untuk menentukan jumlah optimal untuk setiap kali pembelian/pemesanan yang harus dilakukan dan berapa banyak jumlah yang harus dipesan, serta waktu optimal pemesanan kembali dilakukan. Metode EOQ digunakan untuk untuk menghindari resiko kehabisan dan juga kelebihan bahan baku sehingga dapat meminimalisasi biaya bahan baku perusahaan. Reorder Point (ROP) terjadi apabila jumlah persediaan yang terdapat didalam stock berkurang terus sehingga kita menentukan berapa banyak batas minimal tingkat persediaan yang harus di pertimbangkan sehingga tidak terjadi kekurangan persediaan.

Jumlah yang diharapkan tersebut dihitung selama masa tenggang, mungkin dapat juga ditambahkan dengan safety stock yang biasanya mengacu kepada profitabilitas atau kemungkinan terjadinya kekurangan stock selama tenggang ROP atau biasa disebut batas atau titik jumlah pemesanan kembali tersebut permintaan yang diinginkan atau dibutuhkan sebelum masa tenggang, misalnya suatu tambahan atau ekstra stock. Safety stock merupakan metode yang dipelukan untuk mengatasi ketidakpastian dalam permintaan, leed time, dan perubahan pasokan, baik dari sisi jumlah pasokan stok, kualitas, dan waktu pengiriman barang 
dari pemasok. Diharapkan setelah menggunakan metode EOQ, ROP dan Safety Stock pihak PT. Langgeng dapat meminimalisir resiko-resiko yang akan muncul seperti kehabisan stock persediaan maupun kelebihan stock persediaan, juga dapat melakukan perencanaan pembelian terlebih dahulu agar persediaan yang dibeli juga lebih optimal, sehingga mampu menghemat biaya dan mendapat keuntungan.

\section{Pengendalian Persediaan}

Pengertian pengendalian persediaan adalah usaha sistematis perusahaan untuk mencapai tujuan dengan cara membandingkan prestasi kerja dengan rencana dan membuat tindakan yang cepat untuk mengoreksi perbedaan yang penting [8].

Fungsi pengendalian adalah untuk menilai seberapa jauh pelaksanaantugas organisasi telah dilaksanakan sebagaimana tugas-tugas organisasi telah dilaksanakan sebagaimana mestinya sesuai dengan rencana yangditetapkan. Berdasarkan beberapa pengertian yang telah dikemukakandiketahui bahwa pengandalian adalah fungsi manajeman yangdiciptakan untuk mengarahkan kegiatan yang dilaksanakan agar sesuaidengan rencana dan demi tercapainya tujuan perusahaan [1].

\section{Peramalan}

Peramalan adalah proses untuk merencanakan perkiraan kebutuhan dimasa yang akan datang dengan melakukan pengujian pada keadaan dimasa lalu yang meliputi kebutuhan dalam ukuran kuantitas, kualitas, waktu dan lokasi yang dibutuhkan dalam rangka memenuhi permintaan barang ataupun jasa [9].

Dalam ukuran akurasi hasil peramalan tersebut yang merupakan ukuran kesalahan peramalan merupakan ukuran tentang tingkat perbedaan antara hasil peramalan dengan permintaan yang terjadi. Berikut 4 (empat) ukuran yang biasa digunakan, yaitu [9] :

1. Mean Absolute Deviation (MAD)

MAD merupakan kesalahan mutlak selama jangka waktu tertentu tanpa memperhatikan hasil peramalan yang lebih besar atau lebih kecil daripada kenyataannya.

2. Mean Square Error (MSE)

MSE dapat dihitung dengan menjumlahkan kuadrat kesalahan peramalan produksi pada setiap jangka waktu yang sudah ditentukan dan membaginya dengan jumlah periode peramalan.

3. Mean Forecast Error (MFE)

MFE dapat dikatakan sangat efektif dalam perhitungan untuk mengetahui apakah suatu hasil peramalan tersebut selama jangka waktu tertentu terlalu tinggi atau terlalu rendah. Bila diketahui hasil peramalan tidak bisa, maka nilai MFE akan mendekati nol.

4. Mean Absolute Percentage Error (MAPE)

MAPE merupakan ukuran kesalahan yang relatif. Perhitungan MAPE biasanya lebih berarti dibandingkan dengan nilai hasil dari perhitungan MAD karena MAPE menyatakan persentase kesalahan hasil peramalan terhadap permintaan yang aktual selama jangka waktu tertentu yang dapat memberikan informasi persentase kesalahan yang terlalu tinggi atau terlalu rendah.

\section{Metode Economic Order Quantity}

Metode analisis data dalam penelitian ini menggunakan metode Economic Order Quantity (EOQ). Teknik EOQ dapat digunakan untuk membantu menentukan persediaan yang efisien. Dalam penentuan atau pemecahan jumlah pesanan yang ekonomis ini dapat dilakukan dengan 3 cara [2], yaitu:

1. Tabular Approach

Penentuan jumlah pesanan yang ekonomis dengan tabular approach dilakukan dengan cara menyusun suatu daftar atau tabel jumlah pesanan dan jumlah biaya per tahun. Jumlah Pesanan yang mengandung jumlah biaya terkecil merupakan jumlah pesanan ekonomis.

2. Dengan menggunakan rumus (Formula Approach) Cara penentuan jumlah pesanan ekonomis dengan menurunkan di dalam rumus-rumus matematika dapat dilakukan dengan memperhatikan bahwa jumlah biaya persediaan yang minimum. Perhitungan (Economic Order Quantity) EOQ dapat dihitung dengan rumus [4]

$\mathrm{EOQ}=\sqrt{\frac{2 \cdot(D) \cdot(O C)}{C C}}$

Keterangan:

EOQ = Jumlah optimal barang per pemesanan.

$\mathrm{D}=$ Permintaan tahunan barang persediaan dalam unit (Demand).

$\mathrm{OC}=$ Biaya pemesanan $($ Ordering Cost $)(\mathrm{S})$.

$\mathrm{CC}=$ Biaya penyimpanan $($ Carrying Cost $)(\mathrm{H})$.

$\mathrm{Q}^{*} \quad=$ Jumlah barang yang optimum pada setiap pesanan (EOQ).

Untuk dapat menghitung berapa kali perusahaan dapat melakukan pembelian dalam setahun, maka diperlukan adanya perhitungan frekuensi dalam persediaan, dapat dihitung dengan rumus [4], sebagai berikut:

Jumlah pesanan yang diperkirakan $=\frac{D}{Q *}$

Biaya pemesanan $=\frac{D}{Q *} \times S$

Perhitungan untuk menghitung biaya penyimpanan tahunan menurut [7] rumus biaya penyimpanan adalah sebagai berikut:

Biaya penyimpanan $=\frac{Q *}{2} \times H$

Perhitungan untuk menghitung persediaan rata-rata tahunan menurut [7], rumus adalah sebagai berikut :

Persediaan rata-rata $=\frac{Q *}{2}$

3. Graphical Approach

Penentuan jumlah pesanan ekonomis dengan graphical approach, dilakukan dengan cara menggambarkan grafikgrafik carrying cost, ordering cost dalam satu gambar, dimana sumbu horisontal jumlah pesanan (order) pertahun, dan sumbu vertikal besarnya biaya dari ordering cost, carrying cost dan total cost.

\section{Metode Safety Stock}

Tujuannya adalah menentukan berapa besar stock yang dibutuhkan selama tenggang untuk memenuhi besarnya permintaan. Safety Stock ini sama dengan persediaan pengaman. Persediaan pengaman atau penyelamat adalah persediaan tambahan yang diadakan untuk melindungi atau 
menjaga kemungkinan terjadinya kekurangan bahan (Stock Out) [1]. Metode dalam menentukan persediaan pengaman atau Safety Stock yang mempunyai rumus :

$$
S S=\sigma_{D} Z \sqrt{ } L
$$

Keterangan:

$\mathrm{SS}=$ Kuantitas persediaan pengaman

$\mathrm{Z}=$ Tingkat keyakinan yang diinginkan

$\sigma_{D}=$ Standar Deviasi / pemakaian rata-rata

$\mathrm{L}=$ Lead time

\section{Metode Reorder Point}

Reorder Point (ROP) terjadi apabila jumlah persediaan yang terdapat didalam stock berkurang terus sehingga kita menentukan berapa banyak batas minimal tingkat persediaan yang harus di pertimbangkan sehingga tidak terjadi kekurangan persediaan. Jumlah yang diharapkan tersebut dihitung selama masa tenggang, mungkin dapat juga ditambahkan dengan safety stock yang biasanya mengacu kepada profitabilitas atau kemungkinan terjadinya kekurangan stock selama tenggang ROP atau biasa disebut batas atau titik jumlah pemesanan kembali tersebut permintaan yang diinginkan atau dibutuhkan sebelum masa tenggang, misalnya suatu tambahan atau ekstra stock [1].

Titik pemesanan didasarkan pada penggunaan waktu yang diperlukan untuk meminta pembelian, pemesanan dan penerimaan bahan baku, plus cadangan untuk proteksi terhadap kehabisan persediaan. Titik pemesanan dicapai bila jumlah yang tersedia sama dengan kebutuhan yang diperkirakan yaitu saat jumlah persediaan yang tersedia dan jumlah apapun yang akan masuk ke persediaan sama dengan jumlah persediaanyang akan digunakan selama tenggang waktu tunggu dan jumlah persediaan pengaman [3].

Menurut [5], rumus perhitungan dalam menentukan nilai ROP adalah sebagai berikut:

Waktu Pemesanan $=\frac{\text { jumlah hari kerja }}{\text { frekuensi pemeanan }} \ldots . . .$.
Pemakaian rata-rata $Q=\frac{E O Q}{\text { waktu pemesanan }} \ldots .$.
Perhitungan $\mathrm{ROP}=L \times Q$

\section{METODE PENELITIAN}

Jenis dari penelitian ini adalah kuantitatif, dengan menggunakan metode EOQ, ROP dan Safety Stock. Metode EOQ digunakan untuk menentukan nilai ekonomis order untuk kacang kedelai dan metode ROP digunakan untuk menentukan frekuensi priode order jumlah order kacang kedelai per priode, dan juga untuk menentukan waktu order yang ekonomis. Untuk metode Safety Stock digunakan untuk menentukan jumlah stock pengaman untuk menghindari resiko-resiko dari keterlambatan pengiriman dan kehabisan stock kacang kedelai digudang

Dalam penelitian ini juga terdapat beberapa metode peramalan, yang digunakan untuk menentukan jumlah permintaan tahu putih dan tahu goreng. Metode yaitu metode Trend Analysis Quadratic, metode Winter Multilicative, dan metode Double Expontial Smoothings.

Metode pengumpulan data dalam penelitian ini yaitu dengan melakukan wawancara kepada pemilik PT. Langgeng. Penelitian ini juga dilakukan dengan observasi atau pengamatan langsung terhadap proses produksi tahu dan pengendalian bahan baku di PT. Langgeng.

\section{HASIL DAN PEMBAHASAN}

\section{Perhitungan Peramalan}

Hal yang harus dilakukan untuk peramalan permintaan terhadap produk tahu yaitu melihat pola permintaan pada periode sebelumnya. Pola permintaan dilakukan dengan membuat grafik data jumlah permintaan produk tahu putih dan tahu goreng pada periode sebelumnya. Data yang diambil yaitu jumlah permintaan tahu putih dan tahu goreng per minggu pada bulan desember 2020 sampai mei 2021.

Tabel 1. Permintaan Tahu Putih Dan Tahu Goring Priode Bulan Desember 2020 - Februari 2021

\begin{tabular}{|c|c|c|}
\hline \multirow{2}{*}{$\begin{array}{l}\text { Periode } \\
\text { (minggu) }\end{array}$} & \multicolumn{2}{|c|}{ permintaan (unit) } \\
\hline & tahu putih & tahu goreng \\
\hline 1 & 940 & 1020 \\
\hline 2 & 1024 & 1006 \\
\hline 3 & 1000 & 1050 \\
\hline 4 & 1063 & 1047 \\
\hline 5 & 705 & 650 \\
\hline 6 & 687 & 743 \\
\hline 7 & 750 & 750 \\
\hline 8 & 850 & 850 \\
\hline 9 & 930 & 914 \\
\hline 10 & 945 & 935 \\
\hline 11 & 950 & 952 \\
\hline 12 & 1010 & 1005 \\
\hline
\end{tabular}


Tabel 2. Permintaan tahu putih dan tahu goring priode bulan Maret - Mei 2021.

\begin{tabular}{|r|r|r|}
\hline \multirow{2}{*}{ periode (minggu) } & \multicolumn{2}{|c|}{ permintaan (unit) } \\
\cline { 2 - 3 } & tahu putih & tahu goreng \\
\hline 13 & 1448 & 1450 \\
\hline 14 & 1480 & 1470 \\
\hline 15 & 1500 & 1500 \\
\hline 16 & 1500 & 1500 \\
\hline 17 & 1560 & 1554 \\
\hline 18 & 1620 & 1650 \\
\hline 19 & 1670 & 1672 \\
\hline 20 & 1720 & 1730 \\
\hline 21 & 1685 & 1665 \\
\hline 22 & 1704 & 1705 \\
\hline 23 & 1700 & 1708 \\
\hline 24 & 1705 & 1703 \\
\hline
\end{tabular}

\section{Metode Peramalan}

Metode yang digunakan dalam melakukan forecasting (peramalan) menggunakan tiga metode yaitu Metode Trend Analysis Quadratic, Metode Winter Multiplicative, dan Metode Double Expontial Smoothings. Analisis peramalan ketiga metode tersebut menggunakan software Minitab 18. Ketiga metode tersebut akan dibandingkan untuk menemukan peramalan mana yang paling sedikit errornya dilihat dari nilai MSD, MAD dan MAPE. Berikut hasil dari perbandingan ketiga metode tersebut.

Tabel 3. Hasil perbandingan MSD, MAD, dan MAPE Metode Peramalan

\begin{tabular}{|l|c|c|c|}
\hline \multicolumn{5}{|c|}{ TAHU GORENG } \\
\hline \multicolumn{1}{|c|}{ Metode } & MSD & MAD & MAPE \\
\hline DOUBLE EXPONETIAL SMOTHING & 20185.9 & 78 & 7.8 \\
\hline WINTER MULTIPLICATIVE METHOD & 17318.5 & 68.7 & 6.6 \\
\hline TREND ANALISIS QUADRATIC METHOD & 31935.8 & 160.1 & 15.8 \\
\hline \multicolumn{4}{|c|}{ TAHU PUTIH } \\
\hline Metode & MSD & MAD & MAPE \\
\hline DOUBLE EXPONETIAL SMOTHING & 16780.3 & 70.9 & 7 \\
\hline WINTER MULTIPLICATIVE METHOD & 15892.9 & 70.7 & 6.5 \\
\hline TREND ANALISIS QUADRATIC METHOD & 29331.5 & 154.8 & 15.2 \\
\hline
\end{tabular}

Dapat dilihat bahwa nilai MSD (Mean Square Deviation), MAD (Mean Absolute Deviation) dan MAPE (Mean Absolute Percentage Error) dari ketiga metode peramalan yang dilakukan memiliki nilai yang berbeda-beda. Nilai dari MSD (Mean Square Deviation), MAD (Mean Absolute Deviation) dan MAPE (Mean Absolute Percentage Error) pada metode Winter Multiplicative memiliki nilai yang lebih rendah diantara metode yang lain, sehingga metode Winter Multiplicative dipilih sebagai metode terbaik dalam melakukan peramalan permintaan.

\section{Breakdown Permintaan Bahan Baku Kedelai}

Dari hasil peramalan permintaaan tahu putih dan tahu goreng metode terbaik yang digunakan adalah metode Winter Multiplicative. Hasil peramalan permintaan tahu putih dan juga tahu goreng akan menjadi data untuk mengetahui jumlah kebutuhan bahan baaku kedelai untuk perhitungan EOQ, Safety Stock, dan juga ROP untuk mengetahui jumlah ekonomis pemesanan bahan baku kedelai pada bulan Juni sampai dengan November 2021. Berikut adalah data peramalan permintaan tahu putih dan tahu goreng menggunakan metode winter multiplicative: 
Tabel 4. Hasil Peramalan Menggunakan Metode Winter Multilicative

\begin{tabular}{|c|c|c|c|c|}
\hline \multicolumn{5}{|c|}{ Hasil peramalan } \\
\hline $\begin{array}{l}\text { Periode } \\
\text { mingguan }\end{array}$ & Tahu putih & Tahu goreng & $\begin{array}{l}\text { Permintaan } \\
\text { per papan }\end{array}$ & \begin{tabular}{|l|} 
Kebutuhan \\
kedelaiperkg
\end{tabular} \\
\hline 25 & 1647 & 1628 & 3275 & 3602 \\
\hline 26 & 1711 & 1688 & 3399 & 3739 \\
\hline 27 & 1756 & 1719 & 3475 & 3822 \\
\hline 28 & 1844 & 1769 & 3613 & 3974 \\
\hline 29 & 1779 & 1690 & 3469 & 3816 \\
\hline 30 & 1845 & 1751 & 3596 & 3956 \\
\hline 31 & 1891 & 1783 & 3674 & 4041 \\
\hline 32 & 1983 & 1834 & 3817 & 4199 \\
\hline 33 & 1910 & 1752 & 3662 & 4028 \\
\hline 34 & 1980 & 1815 & 3795 & 4174 \\
\hline 35 & 2027 & 1847 & 3874 & 4261 \\
\hline 36 & 2122 & 1900 & 4022 & 4424 \\
\hline 37 & 2042 & 1813 & 3855 & 4240 \\
\hline 38 & 2114 & 1878 & 3992 & 4391 \\
\hline 39 & 2162 & 1911 & 4073 & 4480 \\
\hline 40 & 2261 & 1965 & 4226 & 4649 \\
\hline 41 & 2174 & 1875 & 4049 & 4454 \\
\hline 42 & 2248 & 1942 & 4190 & 4609 \\
\hline 43 & 2297 & 1975 & 4227 & 4699 \\
\hline 44 & 2400 & 2030 & 4430 & 4873 \\
\hline 45 & 2305 & 1937 & 4242 & 4666 \\
\hline 46 & 2382 & 2005 & 4387 & 4826 \\
\hline 47 & 2432 & 2039 & 4471 & 4918 \\
\hline 48 & 2540 & 2095 & 4635 & 5098 \\
\hline Total & 49852 & 44641 & 94493 & 103942 \\
\hline
\end{tabular}

Dari data permintaan tahu goreng dan tahu putih di atas diperoleh jumlah bahan baku kedelai yang dibutuhkan menggunakan perhitungan jumlah kedelai yang diproduksi pada periode sebelumnya dibagi dengan jumlah tahu perpapan yang dihasilkan. Dalam perhitungan tersebut diperoleh hasil dalam 1 (satu) papan tahu goreng dan tahu putih terdapat $1,1 \mathrm{~kg}$ bahan baku kedelai yang terpakai. Maka jumlah permintaan tahu perpapan pada tabel diatas di kali dengan $1,1 \mathrm{~kg}$. diperoleh hasil dari kebutuhan kedelai untuk permintaan tahu putih dan tahu goreng pada tabel di atas.

\section{Pembelian Kedelai}

PT. Langgeng melakukan pembelian kedelai satu minggu sekali dengan waktu pesan sampai dengan datang memakan waktu 1-2 hari. Kedelai yang digunakan adalah kedelai import dari Amerika yang ber merek Bola Kedelai USA No. 1 yang dalam sekarung memiliki berak $50 \mathrm{~kg}$ dengan kualitas yang tinggi untuk hasil tahu yang baik. Adapun data pembelian tahu dalam kurun waktu 3 bulan di PT. Langgeng yang dibagi perminggu adalah sebagai berikut:

Tabel 5. Data Pembelian Bahan Baku

\begin{tabular}{|l|c|c|}
\hline No & Periode pembelian & Pembelian bahan baku kedelai (Kg) \\
\hline 1. & Maret 1 & $3500 \mathrm{~kg}$ \\
\hline 2. & Maret 2 & $3500 \mathrm{~kg}$ \\
\hline 3. & Maret 3 & $3200 \mathrm{~kg}$ \\
\hline 4. & Maret 4 & $3300 \mathrm{~kg}$ \\
\hline 5. & April 1 & $3600 \mathrm{~kg}$ \\
\hline 6. & April 2 & $3900 \mathrm{~kg}$ \\
\hline 7. & April 3 & $4000 \mathrm{~kg}$ \\
\hline 8. & April 4 & $4000 \mathrm{~kg}$ \\
\hline 9. & Mei 1 & $4000 \mathrm{~kg}$ \\
\hline 10. & Mei 2 & $4000 \mathrm{~kg}$ \\
\hline 11. & Mei 3 & $3500 \mathrm{~kg}$ \\
\hline 12. & Mei 3 & \\
\hline \multicolumn{2}{|l|}{ Total pembelian } & \\
\hline \multicolumn{2}{|l|}{ Rata-rata } & \\
\hline
\end{tabular}




\section{Periode Pembelian}

Periode pembelian adalah waktu yang ditentukan perusahaan untuk melakukan pembelian bahan baku setiap kali pemesanan. Untuk pembelian yang ekonimis dan efisien, perusahaan harus tahu berapa banyak unit yang dibeli dan kapan waktu optimal yang digunakan

Tabel 6. Data Periode Pembelian Bahan Baku Kedelai

\begin{tabular}{|c|r|}
\hline pembelian & periode pembelianbahan baku kedelai \\
\hline 1 bulan & $4 \mathrm{kali}$ \\
\hline 3 bulan & $12 \mathrm{kali}$ \\
\hline 6 bulan & $24 \mathrm{kali}$ \\
\hline 1 tahun & $48 \mathrm{kali}$ \\
\hline
\end{tabular}

\section{Biaya Pemesanan}

Di PT. Langgeng sistem yang digunakan dalam proses pemesanan menggunakan metode yang sederhana dan jumlah unit yang tidak tetap setiap melakukan pemesanan. cara yang dilakukan yaitu pemilik pabrik akan menentukan jumlah bahan baku yang akan dipesan untuk periode produksi selanjutnya, setelah itu menghubungi pihak distributor bahan baku kedelai menggunakan telpon, dan pihak dari distributor akan melakukan pengantaran dan transaksi.

Tabel 7. Biaya Pemesanan Bahan Baku Kedelai.

\begin{tabular}{|l|l|r|}
\hline No & Jenis Biaya & Jumlah (Rp) \\
\hline 1. & Biaya telpon & Rp. $50.000 /$ bulan \\
\hline 2. & Biaya antar & Rp. $400.000 /$ bulan \\
\hline \multicolumn{2}{|c|}{ Total } & Rp. $450.000 /$ bulan \\
\hline
\end{tabular}

\section{Lead Time}

Lead time adalah waktu tunggu dalam pemesanana bahan baku dari waktu pemesanan sampai barang yang di pesan datang. Pemesanan bahan baku kedelai di PT. Langgeng memerlukan waktu tunggu selama 2 hari dari waktu pesan sampai bahan baku datang ketempat produksi atau tempat penyimpanan.

\section{Biaya Penyimpanan}

Biaya penyimpanan adalah biaya yang dikeluarkan PT. Langgeng untuk meyimpan bahan baku dalam jangka waktu tertentu, karena PT. Langgeng memiliki periode order 4 kali dalam sebulan maka penyimpanan bahan baku didalam gudang akan mengaalami penurunan stok dan juga peningkatan stok perminggunya.

Tabel 8. Data Biaya Penyimpanan Bahan Baku

\begin{tabular}{|l|c|r|}
\hline No & Jenis Biaya & Jumlah (Rp) \\
\hline 1. & Biaya listrik & Rp. $500.000 /$ bulan \\
\hline 2. & Biaya pengamanan & Rp. $1.000 .000 /$ bulan \\
\hline \multicolumn{2}{|c|}{ Total } & Rp. $1.500 .000 /$ bulan \\
\hline
\end{tabular}

\section{Perhitungan Lot Sizing EOQ}

Lot sizing adalah ukuran pemesanan untuk item. Teknik lot size menetapkan besarnya kuantitas yang dipesan berdasarkan besarnya net requirement. Dalam praktiknya, kuantitas pemesanan item bisa berbeda-beda antar pemasok/penyediaa bahan baku dan hal ini mungkin akan menghasilkan biaya yang berbeda-beda juga tiap teknik lot size.

Berikut adalah perhitungan EOQ dengan menggunakan rumus Formula Approach:

1. Biaya setiap kali pesan

$$
\text { biaya setiap kali pesan }=\frac{\text { total biaya pemesanan }}{\text { frekuensi pemesanan }}
$$

$$
\begin{aligned}
& =\frac{\text { Rp. } 2 \cdot 700 \cdot 000}{24} \\
& =\text { Rp.112.500/pemesanan }
\end{aligned}
$$

Diketahui total biaya pemesanan yang dikeluakan PT. Langgeng pada bulan Juni sampai dengan bulan November 2021 adalah sebesar Rp.2.700.000 dengan frekuensi pemesana 24 kali. Berdasarkan perhitungan biaya yang dikeluarkan setiap kali pesan adalah sebesar Rp.112.500/pemesanan.

2. Biaya Penyimpanan bahan baku

biaya penyimpanan bahan baku $=\frac{\text { total biaya penyimpanan }}{\text { jumlah persediaan bahan baku }}$ 
a. Perhitungan biaya penyimpanan menggunakan data pemakaian bahan baku di PT. Langgeng.

biaya penyimpanan bahan baku $=\frac{R p \cdot 1.500 \cdot 000}{14.733 \mathrm{~kg}}=R p \cdot 102 / \mathrm{kg}$

Diketahui dari data pemakaian bahan baku kedelai pada bulan Maret sampai dengan bulan Mei 2021 pemakaian rata-rata bahan baku perbulan sebanyak $14.733 \mathrm{~kg}$. dalam perhitungan biaya penyimpanan bahan baku diperoleh hasil Rp.102 per kg kedelai yang disimpan di Gudang.

b. Perhitungan biaya penyimpanan menggunakan data hasil perhitungan peramalan

biaya penyimpanan bahan baku $=\frac{\mathrm{Rp} \cdot 9.000 .000}{103.942 \mathrm{~kg}}=R p \cdot 86,58 / \mathrm{kg}$

Dibulakan menjadi Rp. 86/kg. Diketahui PT. Langgeng mengeluarkan total biaya penyimpanan dari bulan Juni sampai dengan bulan November 2021 adalah sebesar Rp.9.000.000 dengan total persediaan bahan baku dari bulan Juni hingga November 2021 sebanyak $103.942 \mathrm{~kg}$ kedelai.

3. Perhitungan EOQ Dengan rumus Formula Approach

$$
\begin{aligned}
E O Q & =\sqrt{\frac{2 \cdot(D) \cdot(O C)}{C C}} \\
& =\sqrt{\frac{2 \cdot(103.942) \cdot(112.500)}{86}} \\
& =\sqrt{271.941 .279,06}=16.490,64 \mathrm{~kg}
\end{aligned}
$$

Berdasarkan data peramalan permintaan tahu diperoleh kedalai yang dibutuhkan sebanyak $103.942 \mathrm{~kg}$, hasil dari perhitungan biaya setiap kali pesan adalah sebesar Rp.112.500 /pemesanan, dan hasil dari perhitungan biaya simpan adalah Rp. $86 / \mathrm{kg}$.

Hasil perhitugan dari EOQ adalah jumlah pemesanan bahan baku berupa kedelai yang dapat dipesan adalah sebanyak 16.490,64 kg yang dibulatkan menjadi 16.491 $\mathrm{kg}$ sehingga biaya yang dikeluarkan lebih ekonomis.

4. Persediaan Rata-rata

$$
\begin{aligned}
\text { Persediaan Rata }- \text { Rata } & =\frac{Q}{2} \\
& =\frac{16.491}{2} \\
& =8.245,5 \mathrm{~kg}
\end{aligned}
$$

Diketahui jumlah pembelian yang diperoleh dari perhitungan EOQ adalah sebanyak $16.491 \mathrm{~kg}$, diperoleh perhitngan persediaan rata-rata bahan baku kedelai sebanyak 8.245,5 kg yang dibulatkan menjadi $8.245 \mathrm{~kg}$.

5. Jumlah pesanan yang diperkirakan

Perhitungan yang diperlukan untuk menghitung jumlah frekuensi pemesanan yang diperkirakan dalam setiap kali pemesanan menurut metode EOQ dengan rumus:

$$
\begin{aligned}
& F=\frac{D}{Q} \\
& F=\frac{103.942}{16.491} \\
& F=6,30 \mathrm{kali}
\end{aligned}
$$

Hasil yang didapat dalam perhitungan frekuensi pesanan yang diperkirakan adalah sebanyak 6,30 kali yang dibulatkan menjadi 6 kali pemesanan dalam rentang waktu 6 bulan. Sedangkan di PT. Langgeng melakukan pemesanan 24 kali dalam 6 bulan, sehingga PT. Langgeng dapat meminimalkan frekuensi pemesanana bahan baku kedelai.

6. Biaya Pemesanan

$$
\begin{aligned}
\text { biaya pemesanan } & =\frac{D}{Q} \times S \\
& =\frac{103.924}{16.491} \times 112.500 \\
& =\text { Rp. } 708.959,43 / 6 \text { bulan }
\end{aligned}
$$

Diketahui jumlah kebutuhan bahan baku kedelai adalah sebanyak $103.942 \mathrm{~kg}$, dengan jumlah pemesanan yang ekonomis hasil dari perhitungan EOQ sebanyak $16.491 \mathrm{~kg}$. Dengan biaya setiap kali melakukan pemesanan sebesar Rp.112.500. berdasarkan perhitungan biaya pemesanan diatas diperoleh jumlah biaya pemesanan yang dapat dikeluarkan PT. Langgeng adalah sebesar Rp.708.959,43 jika dibulatkan menjadi Rp.708.959 / bulan.

7. Biaya Penyimpanan

biaya penyimpanan $=\frac{Q}{2} \times H$

Perhitungan biaya penyimpanan mengguakan data pemakaian bahan baku di PT. Langgeng.

$$
\begin{aligned}
\text { biaya penyimpanan } & =\frac{16.491 / \mathrm{kg}}{2} \times R p .86 / \mathrm{kg} \\
& =R p .709 .113 / \text { bulan }
\end{aligned}
$$

Diketahui bahwa jumlah pemesanan yang ekonomis dengan perhitungan $E O Q$ adalah sebanyak $16.491 \mathrm{~kg}$ dan biaya penyimpanan per $\mathrm{kg}$ adalah sebesar Rp. $86 / \mathrm{kg}$, berdasarkaan perhitungan di atas diperoleh hasil sebesar Rp. 709.113 untuk biaya penyimpanan per 6 bulannya.

\section{Perhitungan Safety Stock}

Safety stock merupakan persediaan pengaman ,guna menghindari resiko-resiko terjadinya kehabisan stok pada saat lead time untuk produksi sehingga tidak dapat memenuhi permintaan konsumen. Perhitungan safety stock diperlukan karena nilai dari safety stock akan menentukan garis dari persediaan minimal yang akan melakukan pemesanan ulang stock bahan baku kedelai. 
Dalam perhitungan standar deviasi demand digunakan rumus excel $=\operatorname{STDEV}($ demand permintaan bahan baku). Hasil dari perhitungan standar deviasi demand bahan baku diperoleh hasil 370.38. Rumus perhitungan safety stock.

$S S=\sigma_{D} \mathrm{Z} \sqrt{\mathrm{L}}$

$S S=370.38 \times 1,645 \sqrt{2}$

$S S=861,64 \mathrm{~kg}$

Dalam penentuan nilai $Z$ yang ditentukan oleh manajemen dari perusahan didapatkan nilai $Z$ sebesar $95 \%$ yang dilihat dari tabel $\mathrm{Z}$ bernilai 1,645, untuk nilai leadtime yaitu sebesar 2 hari, dan untuk nilai standar deviasi demand adalah sebesar 370,38. Hasil perhitungan untuk safety stock

Pemakaian Rata - Rata $=\frac{16.491 \mathrm{~kg}}{26 \text { hari }}=634,26 \mathrm{~kg}$

yang ekonomis dengan menggunakan metode EOQ adalah sebanyak $16.491 \mathrm{~kg}$, dengan pemesanan yang dilakukan setiap 26 hari sekali. Bedasarkan perhitungan diatas diperoleh pemakaian rata-rata sebanyak $634,26 \mathrm{~kg}$ jika dibulatkan menjadi $634 \mathrm{~kg}$. di atas menunjukan hasil $\mathrm{SS}=861,64 \mathrm{~kg}$ yang dibulatkan menjadi $862 \mathrm{~kg}$.

\section{Perhitungan ROP}

Rumus perhitungan dalam menentukan nilai ROP adalah sebagai berikut:

Waktu Pemesanan $=\frac{156}{6}=26$ hari

Perhitungan untuk melakukan pemesanan ulang kembali dengan menggunakan data jumlah hari kerja yaitu 156 hari dalam rentang waktu 6 bulan dan hasil dari perhitungan frekuensi pemesanan menggunakan metode EOQ sebanyak 6 kali dalam 6 bulan. Dalam perhitungan diatas didapatkan hasil sebesar 26 hari sekali melakukan pemesananan ulang.

$$
\begin{aligned}
R O P & =L \times Q+S S \\
& =(2 \times 634)+862 \\
& =2.130 \mathrm{~kg}
\end{aligned}
$$

Berdasarkan perhitungan ROP di atas hasil dari persediaan bahan baku kedelai yang mencapai titik

\begin{tabular}{|c|c|c|c|c|c|}
\hline \multicolumn{6}{|c|}{ Hasil Perhitungan EOQ, Safaty Stock, den ROP } \\
\hline $\begin{array}{l}\text { Periode } \\
\text { mingguan }\end{array}$ & $\begin{array}{l}\text { Stock bahan } \\
\text { balu masuk }\end{array}$ & $\begin{array}{l}\text { Permintaen } \\
\text { bahan baku }\end{array}$ & $\begin{array}{l}\text { Sisa stock: } \\
\text { bahan baku }\end{array}$ & Safaty Stock: & ROP \\
\hline 25 & 16491 & 3275 & 13216 & 862 & 2130 \\
\hline 26 & 0 & 3399 & 9817 & 862 & 2130 \\
\hline 27 & 0 & 3475 & 6342 & 862 & 2130 \\
\hline 28 & 16491 & 3613 & 19220 & 862 & 2130 \\
\hline 29 & 0 & 3469 & 15751 & 862 & 2130 \\
\hline 30 & 0 & 3596 & 12155 & 862 & 2130 \\
\hline 31 & 0 & 3674 & 8481 & 862 & 2130 \\
\hline 32 & 16491 & 3817 & 21155 & 862 & 2130 \\
\hline 33 & 0 & 3662 & 17493 & 862 & 2130 \\
\hline 34 & 0 & 3795 & 13698 & 862 & 2130 \\
\hline 35 & 0 & 3874 & 9824 & 862 & 2130 \\
\hline 36 & 16491 & 4022 & 22293 & 862 & 2130 \\
\hline 37 & 0 & 3855 & 18438 & 862 & 2130 \\
\hline 38 & 0 & 3992 & 14446 & 862 & 2130 \\
\hline 39 & 0 & 4073 & 10373 & 862 & 2130 \\
\hline 40 & 16491 & 4226 & 22638 & 862 & 2130 \\
\hline 41 & 0 & 4049 & 18589 & 862 & 2130 \\
\hline 42 & 0 & 4190 & 14399 & 862 & 2130 \\
\hline 43 & 0 & 4227 & 10172 & 862 & 2130 \\
\hline 44 & 16491 & 4430 & 22233 & 862 & 2130 \\
\hline 45 & 0 & 4242 & 17991 & 862 & 2130 \\
\hline 46 & 0 & 4387 & 13604 & 862 & 2130 \\
\hline 47 & 0 & 4471 & 9133 & 862 & 2130 \\
\hline 48 & 0 & 4635 & 4498 & 862 & 2130 \\
\hline
\end{tabular}
pemesanan kembali adalah sebanyak $2.130 \mathrm{~kg}$.

Tabel 9. Hasil Perhitungan EOQ, Safety Stock Dan ROP 


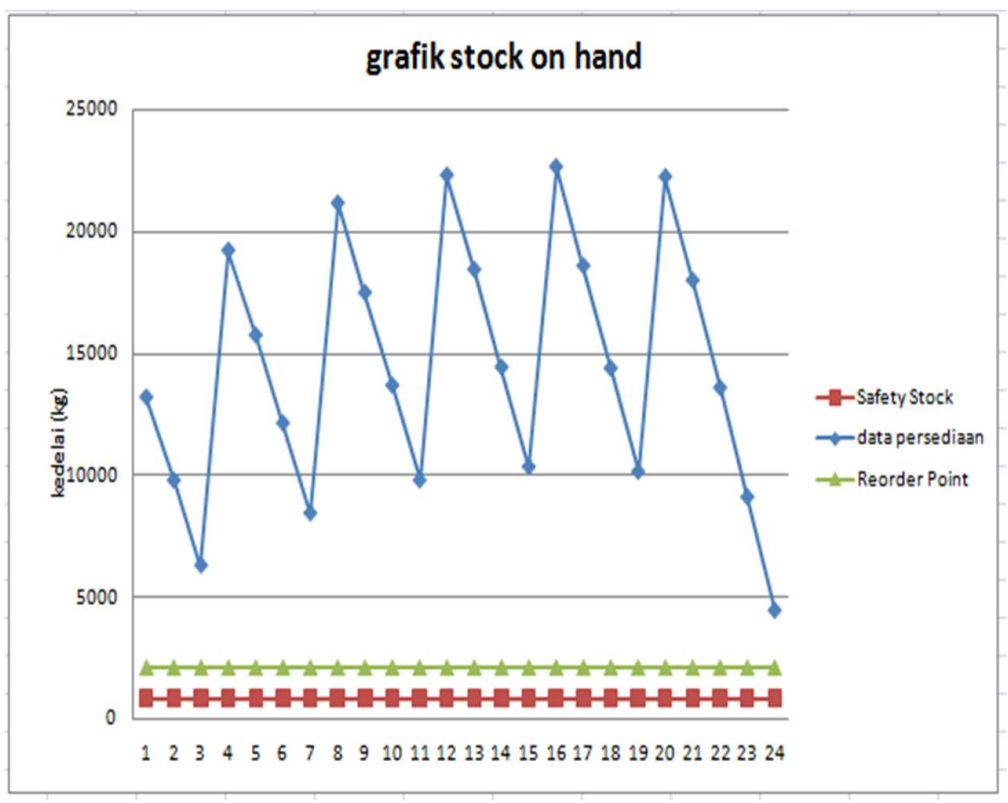

Gambar 1. Grafik Stock On Hand

\section{KESIMPULAN DAN SARAN}

Kesimpulan dalam penelitian ini dengan menggunakan metode EOQ, ROP dan safety stock. Memperoleh hasil yang lebih ekonomis dan dapat menguntukan perusahaan dengan hasil sebagai berikut:

1. MAPE 6,5 dan 6,66 MAD 70,7 dan 68,7 MSD 16780,3 dan 17318,5. Maka peramalan dengan metode winter multiplicative sebagai metode peramalan terbaik. Yang digunakan data untuk menghitung jumlah permintaan bahan baku kedelai dan perhitungan EOQ, SS, dan ROP .

2. Berdasarkan pada perhitungan EOQ menggunakan rumus formula approach diperoleh hasil pemesanan ekonomis sebanyak $16.491 \mathrm{~kg}$ yang jika di bulatkan dalam pembelian kedelai yang memakai kelipatan $50 \mathrm{~kg}$ perkarung maka nilai pemesanan yang ekonomis sebanyak $15.500 \mathrm{~kg}$ dengan 6 kali frekuensi pemesanan dalam 6 bulan yang mengakibatkan penurunan biaya pemesanan dari Rp. 2.700 .000 per 6 bulan menjadi Rp. 708.959 per 6 bulannya, dan juga biaya penyimpanan dari Rp. 1.500 .000 menjadi Rp. 709.113 perbulan jika dalam satuan per $\mathrm{kg}$.

3. Berdasarkan perhitungan safety stock ditentukan nilai $Z$ sebesar 95\% sama dengan 1,645 jika didalam tabel $\mathrm{Z}$. Diperoleh hasil sebanyak $862 \mathrm{~kg}$ stock pengaman jika terjadi resiko perpanjangan leedtime atau permintaan konsumen yang naik. Sehingga PT. Langgeng dapat meminimalisir resiko kehabisan stock atau stock out.

4. Berdasarkan perhitungan ROP di peroleh hasil waktu pemesanan yang ekonomis 26 hari sekali untuk melakukan pemesanan ulang bahan baku, dengan jumlah rata-rata pemakaian bahan baku sebanyak $634 \mathrm{~kg}$. dalam perhitungan ROP diperoleh batas minimum persedian bahan baku untuk mempertimbangkan perusahaan melakukan pemesanan ulang sebanyak $2.130 \mathrm{~kg}$ yang jika stock digudang sudah mencapai angka batas maka perlu dilakukan pemesanan ulang.

\section{DAFTAR PUSTAKA}

[1] Anggraini, I. (REPOSITORY UNIVERSITAS MUHAMMADIYAH PALEMBANG). Analisis Perencanaan Dan Pengendalian Persediaan Bahan Baku Dengan Metode EOQ (Economy Order Quantity) Pada CV. Maju Mapan Lestari. Dipetik 06 26, 2021, dari http://repository.um-palembang.ac.id/id/eprint/576/1/SKRIPSI4091704282672.pdf

[2] Assauri, S. (2009). Manajemen Pemasaran Konsep Dasar dan Strategi. Edisi pertama. Jakarta: PT. Raja Grafindo Persada.

[3] Carter, W. K. (2009). Akuntansi Biaya. Buku 1. Edisi 14. Jakarta: Salemba Empat.

[4] Fahmi, I. (2014). Manajemen Produksi dan Operasi. Bandung: Alfabeta.

[5] Fitriyah, S. (2018). Dipetik 06 10, 2021, dari DOCPLAYER: http://docplayer.info/198674676-Skripsi-analisis-pengendalianpersediaan-bahan-baku-kedelai-pada-pabrik-tahu-makassar-usahabapak-miswan-sri-fitriyah-nim.html

[6] Haming, \& Mahfud. (2007). Manajemen Produksi Modern. Jakarta: Bumi Aksara.

[7] Heizer, J., \& Barry, R. (2010). Manajemen Oprasi Edisi Kesembilan. Jakarta: Salemba Empat.

[8] Milton, F. U., \& Hammer, H. L. (2009). Akutansi Biaya. Edisi 10. Jakarta : Erlangga.

[9] Nasution, A. H., dan Prasetyawan, Y. (2008). Perencanaan \& Pengendalian Produksi. Edisi Pertama. Graha Ilmu, Yogyakarta.

[10] Rangkuty, F. (2008). Manajemen Persediaan. Jakarta: Rajawali. 